\title{
EXPERIMENTAL INVESTIGATION OF NEW DESIGN OF SOLAR WATER DISTILLATION COUPLED WITH FLAT PLATE SOLAR WATER COLLECTOR
}

\author{
Sabah Tarik Ahmed \\ sabahsmrm@yahoo.com \\ Hussein Hayder Mohammed Ali \\ me.20171@uotechnology.edu.iq \\ University of Technology / Mechanical. Eng. Dept.
}

\begin{abstract}
An experimental investigation involves the effect of the turning hollow-cylinder within a solar water distillation on the output of distillate water. This study is to be conducted in order to validate the optimum productivity of purification water by turning hollow-cylinder. The experiments were carried out in Kirkuk city, Iraq, 2018.

Experimental results demonstrated that a basin water height is $(1 \mathrm{~cm})$ gives the better productivity of $\left(1225 \mathrm{ml} / \mathrm{m}^{2}\right.$.day) for the conventional solar water distillation, and $(2 \mathrm{~cm})$ basin water height for the modification solar water distillation gives the optimum productivity which is $\left(3540 \mathrm{ml} / \mathrm{m}^{2}\right.$.day) which represent an increase of $188 \%$ when compared with the productivity of the conventional solar water distillation. $0.5 \mathrm{rpm}$ and $1 \mathrm{rpm}$ are the optimum rpm for the hollow cylinder for the modification solar water distillation without and with flat plate solar water collector. The maximum percentage of productivity obtained from the modification solar water distillation which connected to a solar water heater with automatically varying speed according to the solar radiation intensity (Auto turning + Collector) gives more than $(310 \%)$ enhancement. The estimated cost of one litre distillate water output for modification and conventional solar water distilleries were 136 ID and 175 ID respectively.
\end{abstract}

\section{KEY WARDS: Solar Water Distillation; Hollow Cylinder; Flat Plate Solar Water Collector.}

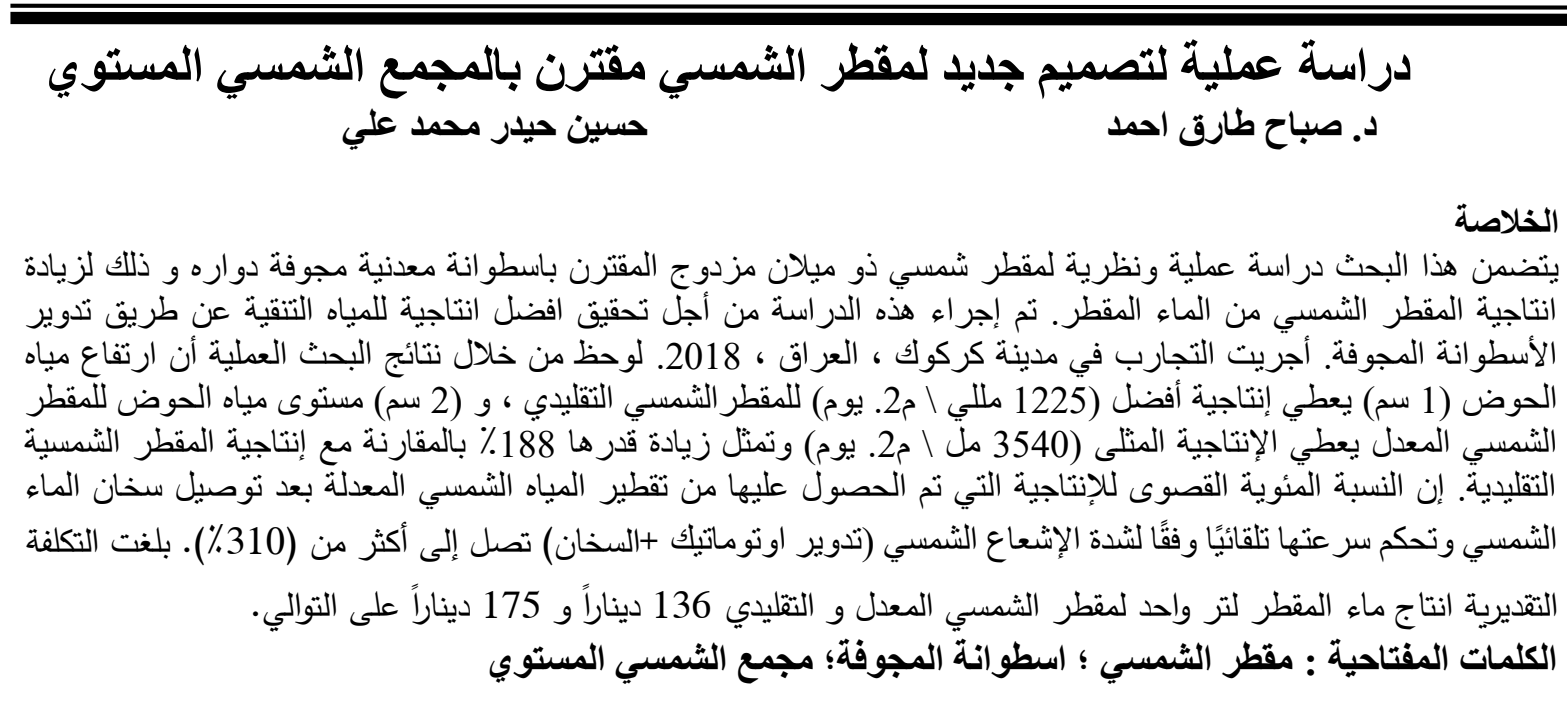

Received:15-8-2019

Accepted:22-9-2019 


\title{
NOMENCLATURE
}

\section{Latin Symbols:}

\begin{tabular}{c} 
Symbol \\
\hline $\mathrm{F}$ \\
$\mathrm{H}$ \\
$\mathrm{L}$ \\
$\mathrm{m}$ \\
$\mathrm{N}$ \\
$\mathrm{T}$ \\
$\mathrm{W}$ \\
$\mathrm{X}$ \\
$\mathrm{Y}$
\end{tabular}

\begin{tabular}{l}
$\frac{\text { Description }}{\text { Fixed cost }}$ \\
Height \\
Length \\
Mass \\
Number of revolutions \\
Temperature \\
Width \\
Variable cost \\
Total cost \\
\multicolumn{1}{c}{ Description } \\
Conventional solar water distillation \\
Cumulative distillate water output \\
Modification solar water distillation \\
Water
\end{tabular}

Abbreviation:

\begin{tabular}{c} 
Symbol \\
\hline DC \\
ID \\
LDR \\
PV \\
rpm
\end{tabular}

\author{
Description \\ Direct current \\ Iraqi dinar \\ Light dependent resistor \\ Photovoltaic panel \\ Revolution per minute
}

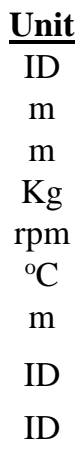

ID

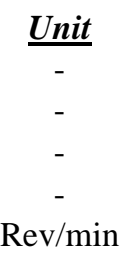

\section{INTRODUCTION}

From historical intervals, a person understood it is useful to make use of solar energy. The solar energy when compared with other energies friendly, clean, much cheaper, renewable energy, available and can be used devoid of surrounding contamination and toxic waste Kalogirou [2009]. Human life needs fresh water, it is very important besides some animals and plants. Notice from the initial 20th century, great industrialized growths and evolution of people while publics existing in rustic regions and villages hurt with little of fresh water. Major reason of polluted water by industrial toxic waste and people living on surface ground. Over a million populaces lack found by the World Health Association that admission to the cleanest drinking water. Furthermore, most of these populaces is living in rustic regions where it is difficult to construct a fresh water solutions system Agrawal et al. [2016]. One of solar energy applications is a solar water distillation for producing a fresh water from a brackish water.

Solar Water Distillation

A solar water distillation is simply equipment for producing a fresh water from a saline water, pollution water or brackish water. Distillation consumes energy from sunlight, it means zero price fuel and use of electricity. Due to diminishing global warming and greenhouse gas emissions problems.

Classification of Solar Water Distillation

There are two main strategies for the solar water distillation which are an active solar water distillation and a passive solar water distillation. This main strategy provisional on the technique of coupling the solar energy. Active solar distillation use solar collectors, photovoltaic boards, and concentrator along with distillation element. Passive solar distilleries directly consumption solar radiation in the solar distillation. All distilleries can be additional obviously categorized as clearly shown in Figure (1) 
Manchanda and Kumar [2015]. Abdel-Rehim and Lasheen [2005] investigated the amendment for the solar distillation system. The amendment was via a rotating shaft fitted to the surface of the basin water. The objective of via rotating shaft to disruption the boundary layer of the basin water surface, thus growing the water evaporation and condensation. The presentation of the amended distillation and the conventional are compared. Results show by rotating shaft $(958 \mathrm{rpm})$ and the PV-scheme was augmented by $2.5 \%, 5 \%$, and 5.5\% in May, June and July. Tarawneh [2007] examined the water production by the influence of basin water height, operational parameters on the solar distillation process and the design. The results showed that increasing water productivity when decreasing basin water height. Hashim et al. [2010] found that the best solar water distillation is that which has symmetric double incline, the best inclination angle was $45^{\circ}$ which give the best accumulative distillate water output of solar water distillation. Panchal and Shah [2012] conducted an experimental study with three similar solar water distilleries. The first solar water distillation as conventional distillation was made from Iron sheets. The final two solar water distillation contains of plates like Galvanized Iron and Aluminum. He found that solar water distillery having Galvanized iron plate increases distillate water production by $15 \%$ and Aluminum sheet increases up to $45 \%$ compared with conventional solar water distillation. Ayoub et al. [2014] conducted study a simple improvement, increasing the evaporative surface area, in the form of a slowly-rotating drum. This new improved distillate was evaluated in terms of both economic probability and operation. The presented cylinder resulted in a $200-300 \%$ increase in water output. The target of this work is also to obtain the augmentation of production of purification water by using a solar water distillation. This work is considered as a pioneer attempt to specify partly immersed slowly- turning hollow-cylinder according to solar radiation intensity is introduced into a distillation.

\section{EXPERIMENTAL WORK}

The experimental rig which constructed were conventional and modification solar water distillation. The modification solar water distillation was manufactured in order to examine experimentally the effects of an augment design and integrated flat plate solar water collector on the performance of the solar water distillation. The solar water distillation system employed in this experimental work was consisted of a partly submerged slowly - turning hollow cylinder which is introduced into the basin distillation which covered by glass and flat plate solar water collector work as a water heater unit. Figure (2) illustrated a schematic diagram for the modification apparatus and Figure (3) is a photo to the rig. The experimental work is carried out at the selected weather conditions and operating factors of Kirkuk situate, Iraq, latitude $35.47^{\circ} \mathrm{N}$ and longitude $44.39^{\circ}$ E. The experiments were performed during two months..

\section{Design of the Experimental Apparatus The Conventional Solar Water Distillation}

The experimental conventional solar water distillation can be described as an insulated basin by fabric glass with thickness $(0.05 \mathrm{~m})$. The basin distillation was chosen with dimensions $(\mathrm{L}=1.32 \mathrm{~m}, \mathrm{~W}=0.78$ $\mathrm{m}$ and $\mathrm{H}=0.15 \mathrm{~m})$. It has effective basin area of $\left(1 \mathrm{~m}^{2}\right)$ and it is fabricated using galvanized steel material and painted matter black color in order to increase solar absorbent. A glass cover with an inclination of $(0.9 \varnothing)$ was $32^{\circ}$ to the horizontal according to Duffie [1980] as illustrated in Figure (4). Where $\emptyset$ is $\left(35.47^{\circ}\right)$ for Kirkuk city, Iraq. The glass inclination is fixed to the top of the vertical glass walls and then stable of the basin distillation using a rubber gasket. The windows glass cover has (4 $\mathrm{mm}$ ) thickness and channel to assemble distillate water to out gallon.

\section{The Modified Solar Water Distillation}

The modified solar water distillation can be described as an insulated basin distillation coupled with flat plate solar water collector with well isolated all connections tubes. A basin distillation and glass 
cover were chosen identical to conventional solar water distillation. A partly immersed slowly turning hollow-cylinder is introduced into a distillation in order to validate the optimum production by turning hollow-cylinder according to solar radiation intensity. Where the turning of hollow-cylinder is proportional to sun light intensity. The turning hollow cylinder installed close and immersed to the basin water. As it turns, a thin film of water is formed around its circumference (both the internal and external) and this film will easily evaporate due to the high temperature of the hollow cylinder surfaces, which is fabricated from Aluminum sheet which is cheap, rust resistant, nontoxic, light weight and sustainable heat absorbing metal with higher thermal conductivity. The sheet was chosen with dimensions ( $\mathrm{L}=2.08 \mathrm{~m}, \mathrm{~W}=1.22 \mathrm{~m}$ and $0.001 \mathrm{~m}$ thickness $)$ bend to hollow cylinder shape with dimension $(\mathrm{d}=0.66 \mathrm{~m}$ and $\mathrm{L}=1.22 \mathrm{~m})$ has an effective area external and internal $\left(5 \mathrm{~m}^{2}\right)$. The hollow cylinder was fixed and turning by Aluminum hollow shaft and mounting between two general bearings were $(0.05 \mathrm{~m})$ diameter. At the end of the rotating shaft light pulley fixed $(0.24 \mathrm{~m})$ in diameter. The rotating pulley can be drive by pulley $(0.06 \mathrm{~m})$ in diameter fixed on shaft of DC motor. A DC motor drive rotating hollow cylinder by V-belt which consume (12 V) and (0.13-2.59 A) and has $(5.5 \mathrm{~N} . \mathrm{m})$. The DC motor interface with drive controller circuit, which consists of a variable resistance volume switch to provide the necessary current and voltage to drive the DC motor which can be powered by charge controller, battery and photovoltaic panel. A Photovoltaic of (12 V DC) with a peak power $(150 \mathrm{~W})$, was used for supplying electric power to the charge controller. The use of battery requires the installation of another essential element called the solar charge controller. A battery was uninterruptible power supply used for supplying electric power to the drive controller DC motor and water pump special at absent solar radiation.

\section{The Drive Controller DC Motor}

A drive controller DC motor was used to control speed turning hollow cylinder according to solar intensity. The drive controller accelerates turning hollow cylinder with increasing solar intensity and retardation turning hollow cylinder with decreasing solar intensity by solar intensity sensor. The solar intensity sensor is a photoresist (or light-dependent resistor (LDR) or photo-conductive cell) is a lightcontrolled variable resistor. The resistance of a photoresist decreases with increasing incident solar radiation intensity; in other words, it exhibits photoconductivity. In the dark, their resistance is very high, sometimes up to $1 \mathrm{M} \Omega$, but when the LDR sensor is exposed to light, the resistance drops dramatically, even down to a few ohms, depending on the solar radiation intensity. LDR have a sensitivity that varies with the wavelength of the light applied and are nonlinear devices. The LDR sensor are Semiconductor, which it is a high precision integrated circuit solar intensity sensor. The output voltage of this sensor is linearly proportional to the solar intensity. The LDR does not require any external calibration. Also, it provides a typical variable resistance volume switch $(50 \mathrm{~K} \Omega)$ to change resist in circuit lead to varying current and voltage to drive the DC motor. A drive controller powered by charge controller as illustrate in electric diagram Figure (5).

\section{The Flat Plate Solar Water Collector}

The flat plate solar water collector was used to preheat the basin water which will led to augmentation in evaporation process and so improve output of distillate water. The flat plate solar water collector was chosen with dimensions ( $\mathrm{L}=1.85 \mathrm{~m}, \mathrm{~W}=1 \mathrm{~m}$ and $\mathrm{H}=0.11 \mathrm{~m})$. 


\section{The Measuring Instruments}

\section{The Tachometer Measurement}

A Photo/contact tachometer with a range of (0 to $30000 \mathrm{rpm}$ ) DT-2236B -type was used to measure the number of revolutions of turning hollow cylinder for modification solar water distillation.

\section{The Intensity Solar Radiation Measurement}

A solar power meter with a range of (0 to $\left.3000 \mathrm{~W} / \mathrm{m}^{2}\right)$ TES-1333-type was used to measure the intensity solar radiation over the flat plate solar water collector and solar water distillation.

\section{The Temperature Measurement:}

The thermocouples type-K were used for the temperature measurements. All thermocouples were connected to selector switch and then digital temperature reader (TES-1310A) Type-K.

\section{The Scaled Cylinder}

A scaled cylinder with a range of (100 to $1000 \mathrm{ml})$ each scaled has $(10 \mathrm{ml})$ was used to measure the cumulative distillate water output through the solar water distillation.

\section{RESULTS AND DISCUSSION}

Different experimental tests were done to investigate the different effect on the performance of the solar water distillation. These experiments can be summarized as following: -

1- Testing the performance of solar water distillation with and without the turning hollow cylinder.

2- Testing the performance of solar water distillation for different basin water thickness.

3- Testing the performance of the number of revolutions per minute of the turning hollow cylinder.

4- Testing the effect of water preheating in the flat plate solar water collector on the performance of the solar water distillation.

5- Testing the solar water distillation with and without auto turning system.

\section{Basin Water Height (With and Without Turning Hollow Cylinder):}

Figure (6) clarifies the experimental results for the solar water distillation data at different basin water height and productivity for each point which is obtained at constant initial water supply temperature. A decrease in thickness of water layer in the base will raise the water temperature in the base which is required to evaporative therefore we see an increase in the quantity of evaporated water while decreasing in the basin water height in the conventional solar water distillation. An increase in thickness of water layer in the base causes a decrease in productivity process which is identical with literature survey Tarawneh [2007] and Ayoub et al. [2014]. Figure (6) indicates that a basin water height of $(1 \mathrm{~cm})$ gives better productivity of $\left(1225 \mathrm{ml} / \mathrm{m}^{2}\right.$.day), this trend is also observed in a productivity drop as the higher basin water height of $(7 \mathrm{~cm})$ was only $\left(800 \mathrm{ml} / \mathrm{m}^{2}\right.$.day $)$. Referring to Figure. (7) and Figure (6):

1- $\quad$ It is observed from Figure (7) that the minimum rate of productivity at basin water height of $(1 \mathrm{~cm})$, because the turning hollow cylinder is not in touch with water layer in the base, and also the hollow cylinder will hide solar rays for the base.

2- $\quad$ After $(2 \mathrm{~cm})$ basin water height approximately the same pattern of productivity as increasing the basin water height, in other words decreasing thickness of water layer in the base, will increasing productivity due to quick raise of the water temperature in the base and subsequently quickly evaporation.

3- It is indicating that the distillate water output of modification distillation increasing with high quantities of productivity about (170\%-190\%). This is due to the thin film of water carried around its two faces both the internal and external of turning hollow cylinder so the addition of surface area 
which lead faces area of turning hollow cylinder for inner and outer whereat turning hollow cylinder, meaning continuous boost surface area that evaporate water from it so it is approve with results of the literature review Ayoub and Maleab [2014].

4- It is obvious that at $(2 \mathrm{~cm})$ basin water thickness level for the modification solar water distillation gives the optimum productivity which is $\left(3540 \mathrm{ml} / \mathrm{m}^{2}\right.$.day) and represent an increase of $188 \%$ when compared with the productivity of the conventional solar water distillation at the same basin water thickness level. This is due to increasing the surface area of evaporation and leads to augmentation of production as mentioned before.

5- $\quad$ For the conventional solar water distillation, the optimum basin water thickness is $(1 \mathrm{~cm})$ as shown in Figure (6), and $(2 \mathrm{~cm})$ for the modification solar water distillation as shown in Figure (7).

\section{Number of Revolutions of Turning Hollow Cylinder:}

Figure(8) represents the relation between the effects of a number of revolutions of turning hollow cylinder on a cumulative distillate water output. The Figure shows an augmentation of a cumulative distillate water output as decreasing the number of revolutions of turning hollow cylinder. This is due to the increase in the temperature of the thin water layer carried on by the two surfaces of the turning hollow cylinder due to large period explosion to solar rays which leads to rapid evaporation and the productivity reach to $\left(3575 \mathrm{ml} / \mathrm{m}^{2}\right.$.day) for $(0.5 \mathrm{rpm})$ when compared to $\left(2455 \mathrm{ml} / \mathrm{m}^{2}\right.$.day) for (10 $\mathrm{rpm})$ and $\left(1245 \mathrm{ml} / \mathrm{m}^{2}\right.$.day) for the conventional solar water distillation.

\section{Number of Revolutions of Turning Hollow Cylinder Coupled with Flat Plate Solar Water Collector}

Figure (9) show common pattern augmentation productivity when preheating of water in the base by the flat plate solar water collector which is about (146-260\%) at different number of revolutions from (0.5-10 rpm) similar a cumulative distillate water output to Figure (8). Only it is noted that when the speed is $(0.5 \mathrm{rpm})$ the productivity decreases from the speed $(1 \mathrm{rpm})$. This is because preheating of water with low turning will cause acceleration in the evaporation process of the water layer adhere to the two surfaces of the hollow cylinder in $(0.5 \mathrm{rpm})$ and therefore that quantity of water adheres to the two surfaces of a hollow cylinder in $(0.5 \mathrm{rpm})$ are lower quantity of water adhesion in $(1 \mathrm{rpm})$.

\section{Turning and Auto turning collectors}

The variety of a cumulative of distillate water output for the modified solar water distillation with turning speed for different modes of operation (six modes) is illustrated in Figure (10). It seems that the best performance of distillation process was observed according to the sequence from the modification solar water distillation after connecting flat plate solar water collector and that vary speed automatically according to the solar radiation intensity (Auto turning + Collector) equal rate of (3895-5160 ml $/ \mathrm{m}^{2}$.day). The second mode (Turning + Collector) which means the constant turning speed with variety solar radiation intensity. The third mode of the solar water distillation is the (Auto turning) where the speed varies with solar radiation intensity without preheating in the solar heater. The fourth mode (Turning only) represents the constant turning speed of the hollow cylinder without the collector. Fifth mode (neither constant speed nor automatically) denoted solar water distillation connected to flat plate solar collector without turning. These all compare with the conventional solar water distillation (sixth mode). Figure (11) shows clearly the increment of percentage of solar distillation productivity thought for the operating condition in Figure (10). Detected clearly increasing in productivity according to sequence from distilleries that connected with solar water heater nor turning to the maximum rate that solar distillation after connected solar water heater and that vary 
speed automatically according to the solar radiation intensity (Auto turning + Collector) reach to more than $(310 \%)$ that was the maximum percentage of productivity obtained when compare with previous researcher Ayoub and Malaeb [2014]. Figure (11) shows that connecting solar water heater with solar water distillation will lead to improvement of $(65 \%)$ when compared with conventional solar water distillation. this is due to the increase in base water temperature, which augment evaporation. For the only turning mode, the increase in productivity is (94-186\%) is due to the increase surface area (surface evaporation) according to the increasing the number of revolutions which also lead to decreasing the thickness of the water layer in the surface of the hollow cylinder. The increase in the productivity of mode number (2) is (227\%) when compared with mode number (5). When comparing the mode number (1) with mode number (5) the increasing is (248\%), with mode number (4) is (127\%), and with mode number (3) is (109\%) and with mode number (2) is $(21 \%)$. In the present work, a modification solar water distillation that (Auto turning + Collector) mode is selected as the best mode because it gives (313\%) increment when compared with conventional solar water distillation. Hence can be describe the varieties of modes from first to fifth as following:

First [mode (1)]: - This mode Collect the features of the two modes number (3) and number (5) which preheating water in the collector and auto turning of the hollow cylinder according to solar radiation intensity. This will cause additional the surface area, the reduction of water layer and the restitution of evaporation water with increase intensity of solar radiation, additional layer adding from water as well as accelerate turning when increase intensity of solar radiation.

Second [mode (2)]: - This mode, collecting topographies of mode number (4) and mode number (5) in which preheated the basin water and constant speed turning hollow cylinder. Which causes additional surface area and decrease of water layer.

Third [mode (3)]: - The automatically turning means changing rotating speed with varying intensity of solar radiation, which it is accelerated with increase intensity of solar radiation will lead to accelerate evaporation processes from both surfaces of the hollow cylinder. Both surfaces so need additional layer water as possible in order to augment the evaporation process when increasing turning speed.

Fourth [mode (4)]: - Turning only the hollow cylinder will increase the productivity of the solar water distillation due to the increasing the surface area of evaporation from both surfaces of the hollow cylinder and decreasing thickness of water layer adhere on the both surfaces.

Fifth [mode (5)]: - Augmentation of productivity by preheating of basin water temperature by a flat plate solar water collector. Figure (12) indicates the variation of consumption electric power for turning hollow cylinder of the modification solar water distillation. It seems that consumption power increase with increase turning speed and this is consistent with logic.

\section{ECONOMIC PROBABILITY OF SOLAR WATER DISTILLERIES} Economic Probability of Conventional Solar Water Distillation:

The total fixed cost $(F)$ of conventional solar water distillation in (Iraqi Dinar $=$ ID) is gives in Table (1) about ( $\mathrm{F}=190,000$ ID) To obtain the average value of the cost of cumulative distillate water output, it is important to assume that the variable cost $(\mathrm{X})$ and the total cost (Y) is calculated as Minasian and AL-Karaghouli [1995]: -

$$
Y=F+X
$$

Assume variable cost $(\mathrm{X})$ equals $0.3 * \mathrm{~F}$ per year and the expected solar water distillation life time is 20 years, then $\mathrm{Y}=190,000+0.3 * 190,000 * 20=1330000$ ID. The minimum average daily cumulative distillate water output can be founded from the experimental tests data, and it is calculated as $1245 \mathrm{ml} /$ day based on basin water thickness $1 \mathrm{~cm}$. To calculate the productivity cost for one liter assuming that the conventional solar water distillation runs 
305 days in the year, where the sunny day along the year in Kirkuk, Iraq. The total cumulative distillate water output during the solar water distillation life time $1.245^{*} 305^{*} 20$ $=7594.5$ liters. Then the cost of one liter from conventional solar water distillation $=$ $1330000 / 7594.5=175$ ID $/$ lit.

\section{Economic Probability of Modification Solar Water Distillation:}

The total fixed cost of modification solar water distillation with photovoltaic panel, battery, flat plate solar water collector and others is gives in Table (1) about $F=477,000$ ID. Assume the expected solar water distillation lifetime is 20 years. It is also assumed that $\mathrm{X}=0.3 * \mathrm{~F}$ per year, then $\mathrm{Y}=477,000+0.3 * 477,000 * 20=3339000$ ID. The minimum average daily cumulative distillate water output can be founded from the experimental tests data, and it is calculated as $4025 \mathrm{ml} /$ day based

on basin water thickness $2 \mathrm{~cm}$. Assume solar water distillation runs 305 days in the year. The total cumulative distillate water output during the modification solar water distillation life time $4.025 * 305 * 20=24552.5$ liters. Then the cost of one liter from modification solar water distillation $=3339000 / 24552.5=136$ ID $/$ lit. Table (1). The fixed cost of materials used in the conventional and modification solar water distillation.

\section{CONCLUSION}

As a result of the experimental investigations which were carried out to study the optimum production by turning hollow cylinder according to solar radiation intensity is introduced into a solar water distillation, the following conclusions can be made:

1. A basin water height of $(1 \mathrm{~cm})$ gives better productivity of $\left(1225 \mathrm{ml} / \mathrm{m}^{2}\right.$.day) for the conventional solar water distillation, and $(2 \mathrm{~cm})$ basin water thickness level for the modification solar water distillation gives the optimum productivity which is $\left(3540 \mathrm{ml} / \mathrm{m}^{2}\right.$.day) and represent an increase of $188 \%$ when compared with the productivity of the conventional solar water distillation. 2. The decreasing a number of revolutions of turning hollow cylinder leads to rapid evaporation and increasing the productivity reach to $\left(3575 \mathrm{ml} / \mathrm{m}^{2}\right.$.day) for $(0.5 \mathrm{rpm})$ when compared to (2455 $\mathrm{ml} / \mathrm{m}^{2}$.day) for (10 rpm).

3. When turning hollow cylinder coupled with flat plate solar water collector the augmentation of productivity about (146-260\%) at different number of revolutions from $(0.5-10 \mathrm{rpm})$, at the speed $(0.5 \mathrm{rpm})$ decrease productivity from speed $(1 \mathrm{rpm})$.

4. The modification solar water distillation after connecting flat plate solar water collector and that vary speed automatically according to the solar radiation intensity (Auto turning + Collector) equal rate of (3895-5160 ml/ $\mathrm{m}^{2}$.day).

5. The maximum percentage of productivity obtained from the modification solar water distillation after connected solar water heater and that vary speed automatically according to the solar radiation intensity (Auto turning + Collector) reach about more than $(310 \%)$. 


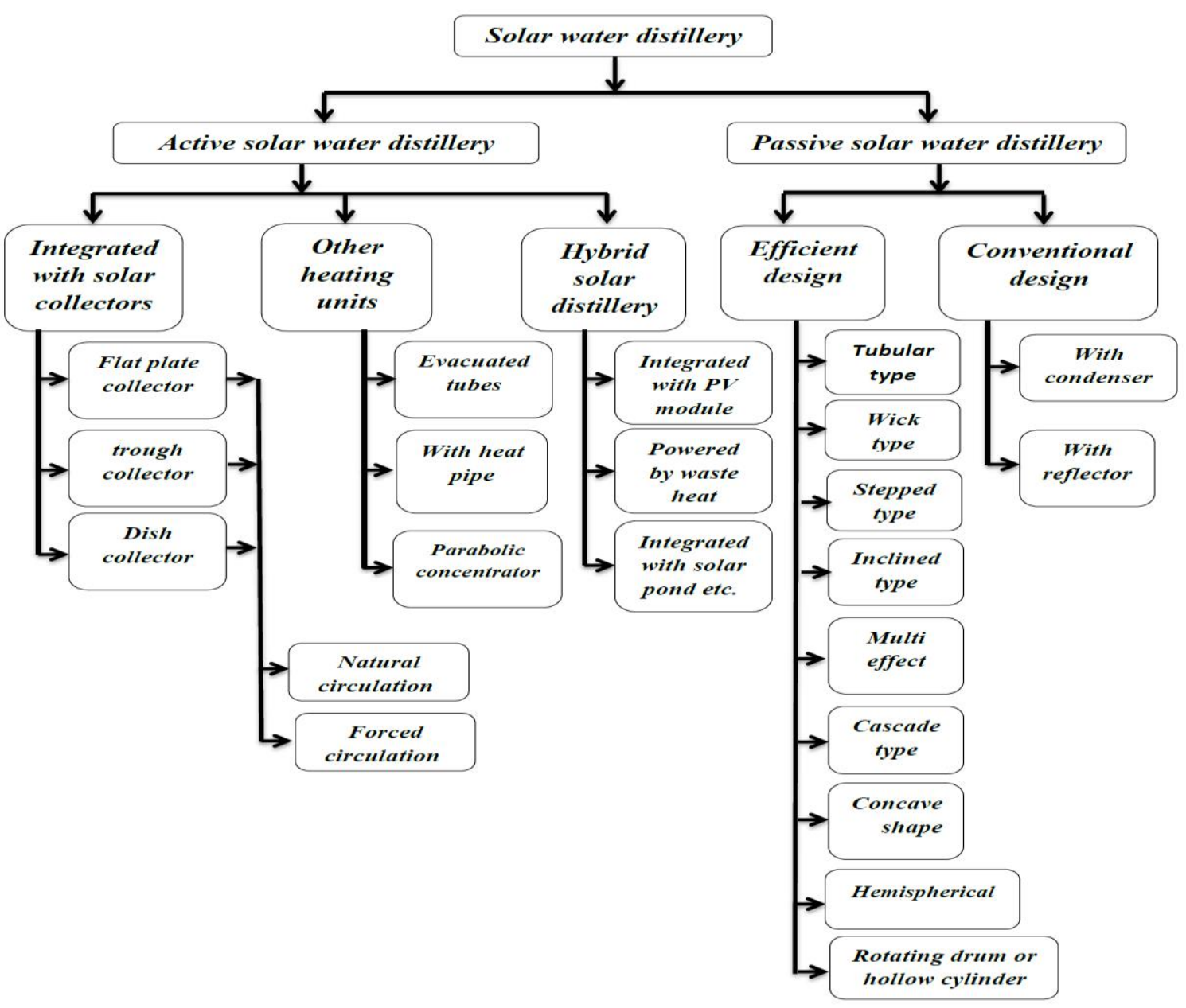

Fig. (1). Simplified classification of solar water distillation

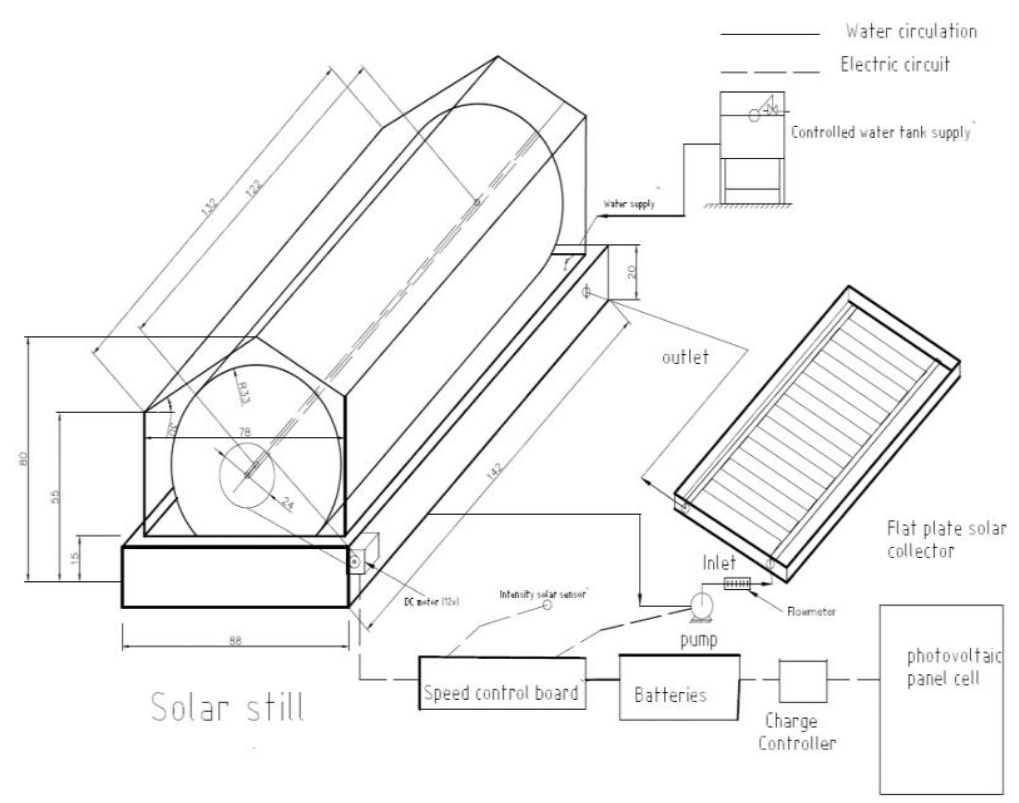

Fig. (2). Schematic diagram of rig test of the modification solar water distillation 


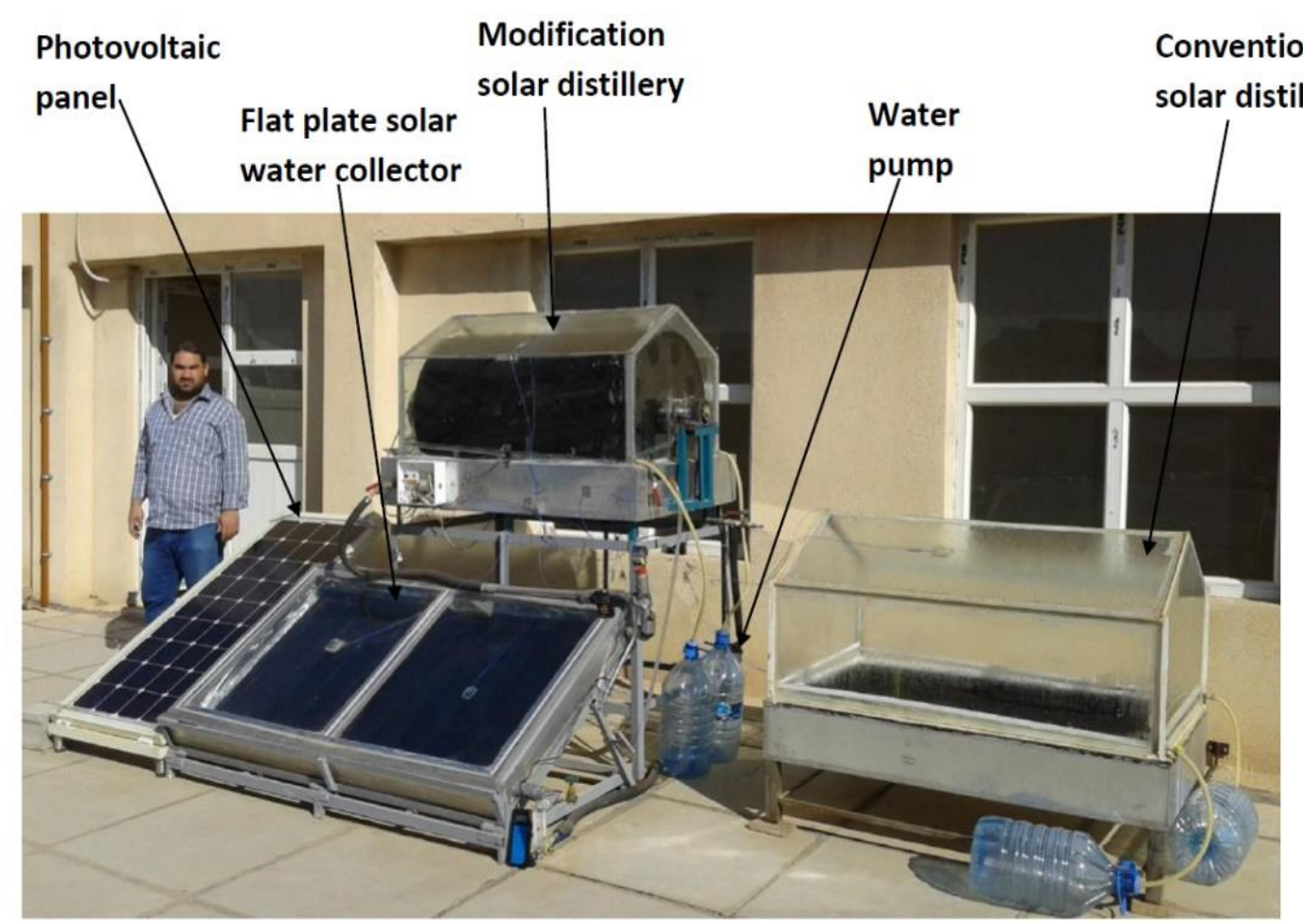

Fig. (3). Photo of the test rig.

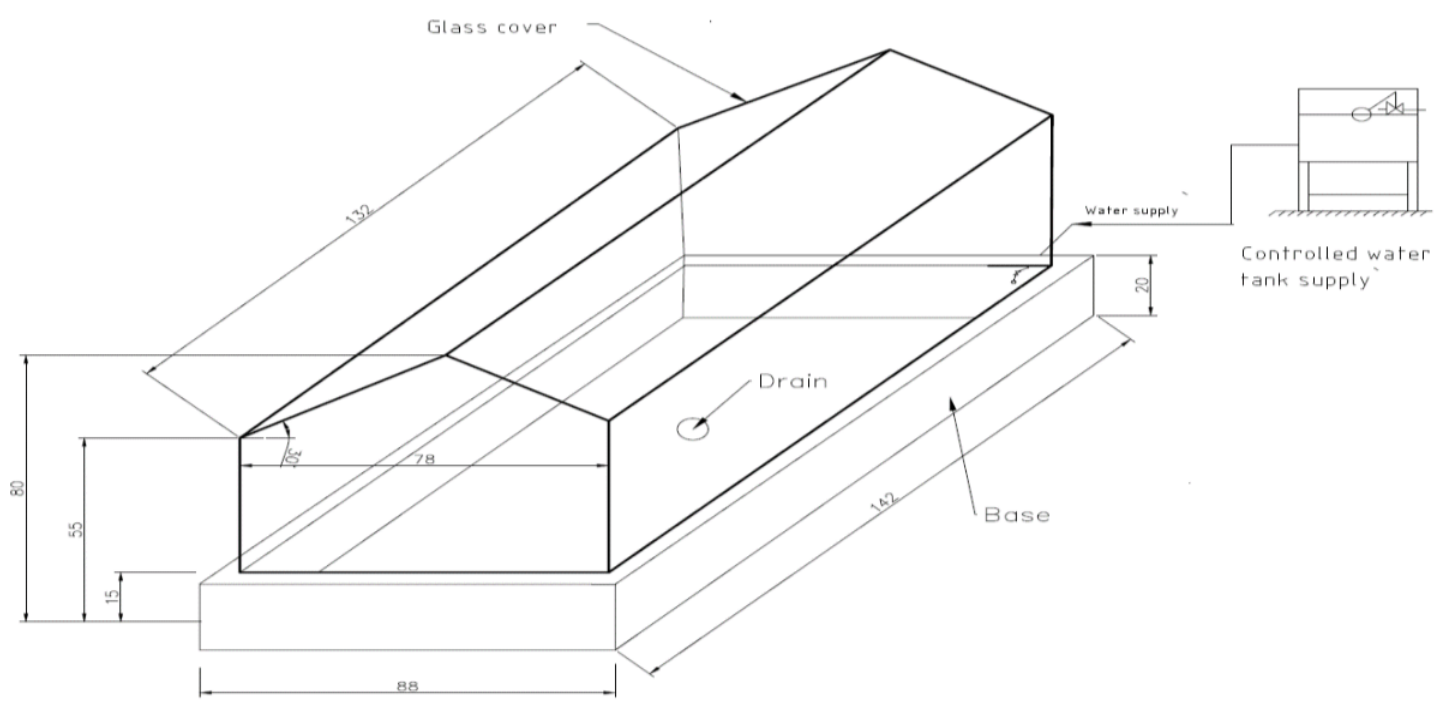

Fig. (4). A schematic diagram for the conventional solar water distillation apparatus. 


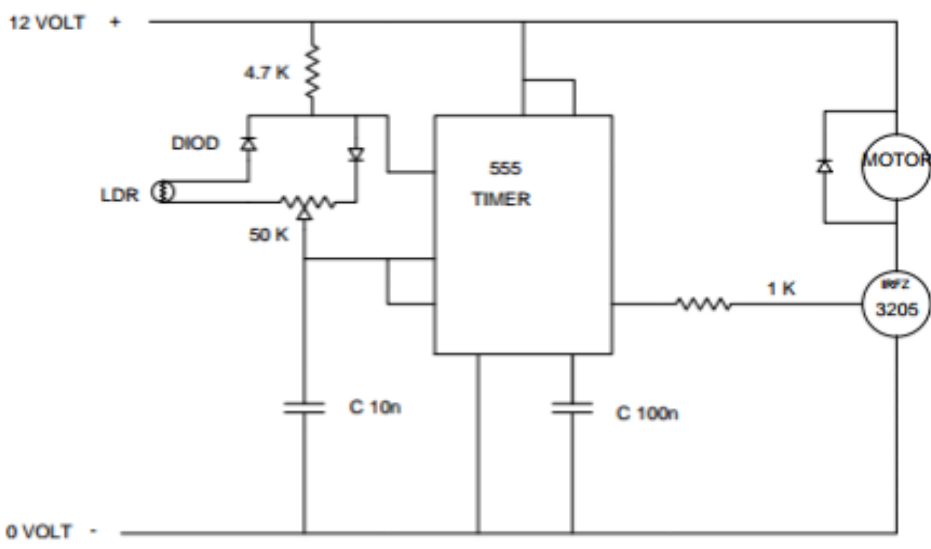

Fig. (5). The electric diagram of drive controller DC motor.

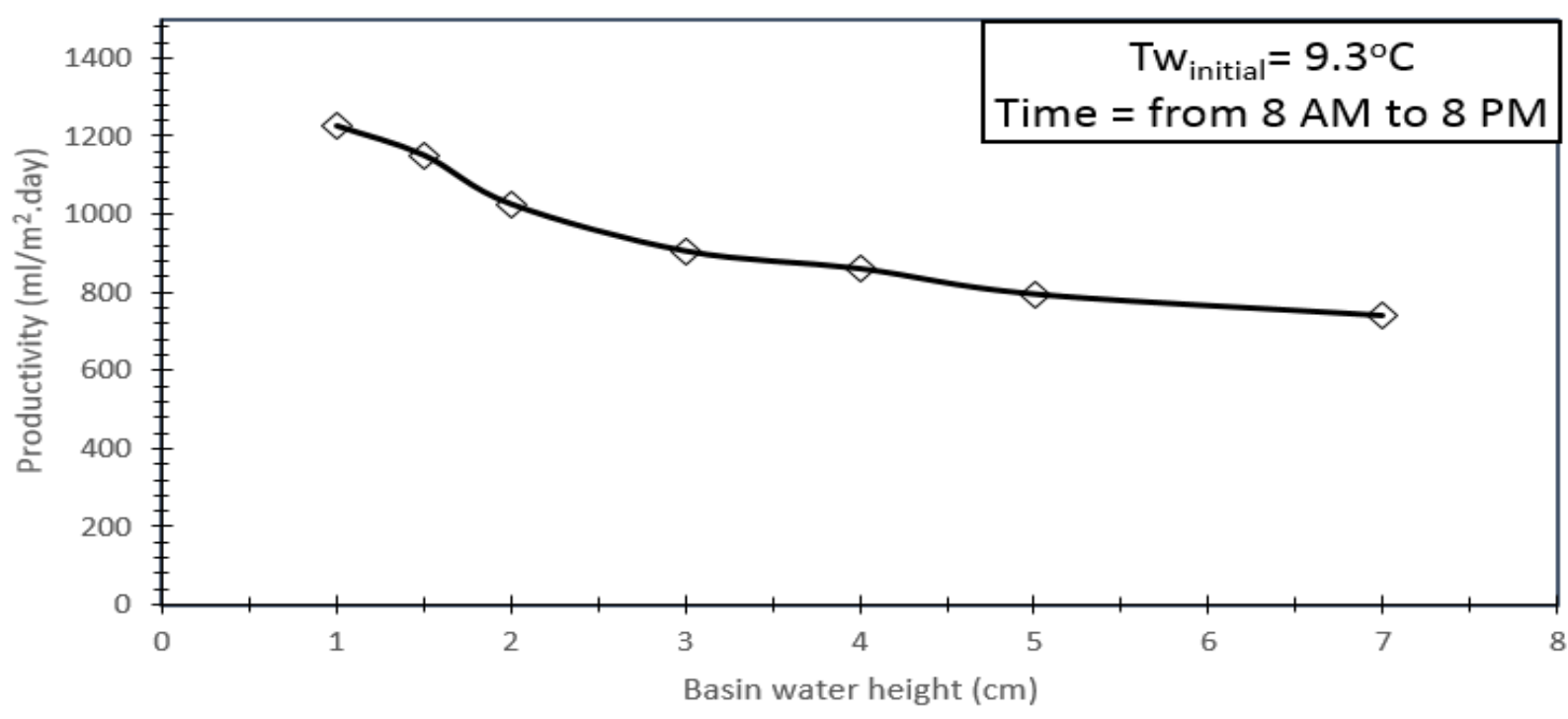

Fig. (6). Basin water height effect on water a cumulative distillate water output for (conventional solar water distillation), (Jan. 2-9 2018, Kirkuk, Iraq)

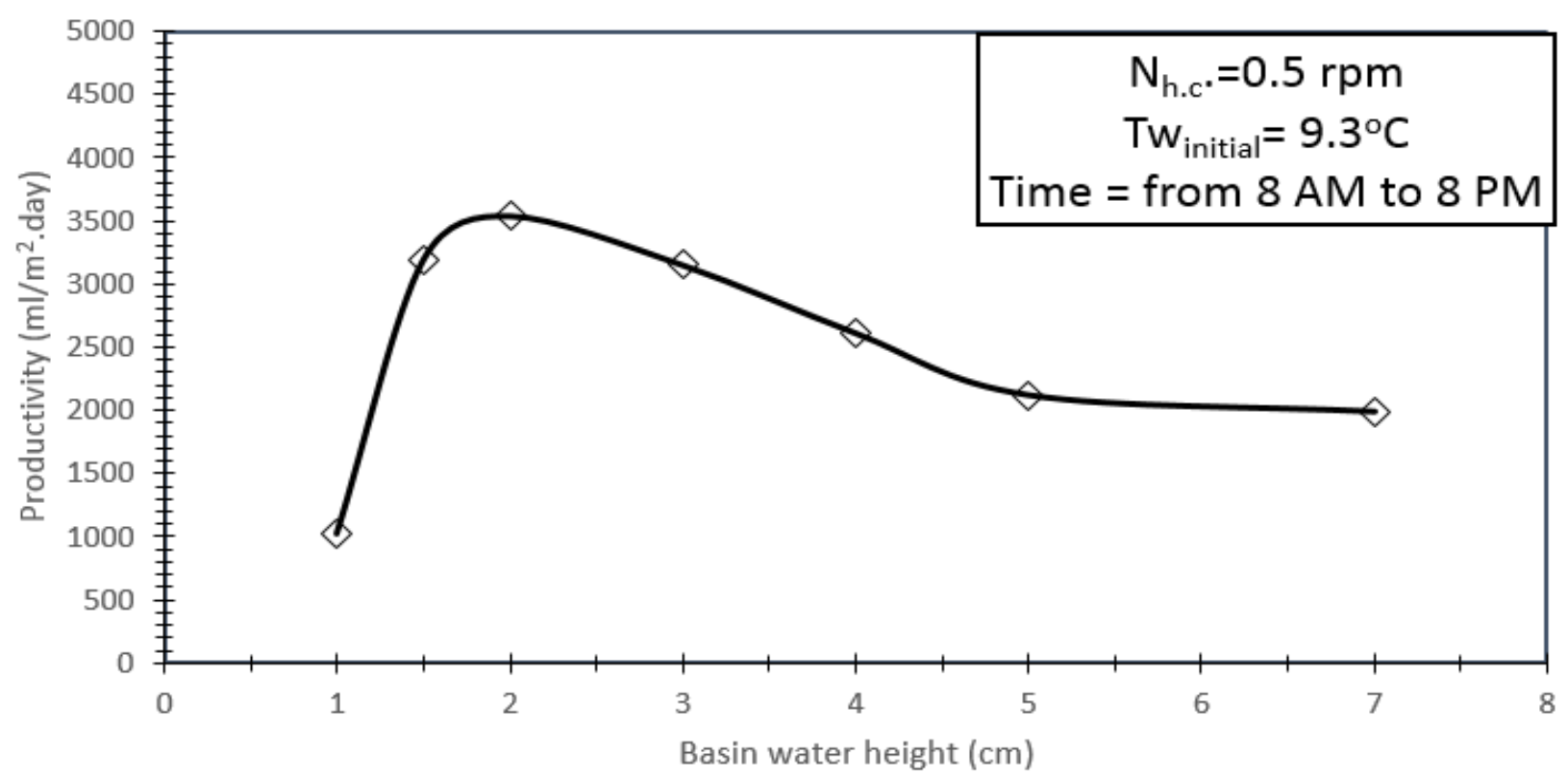

Fig. (7). Basin water height effect on the cumulative distillate water output for modification solar water distillation), (Jan. 2-9 2018, Kirkuk, Iraq). 


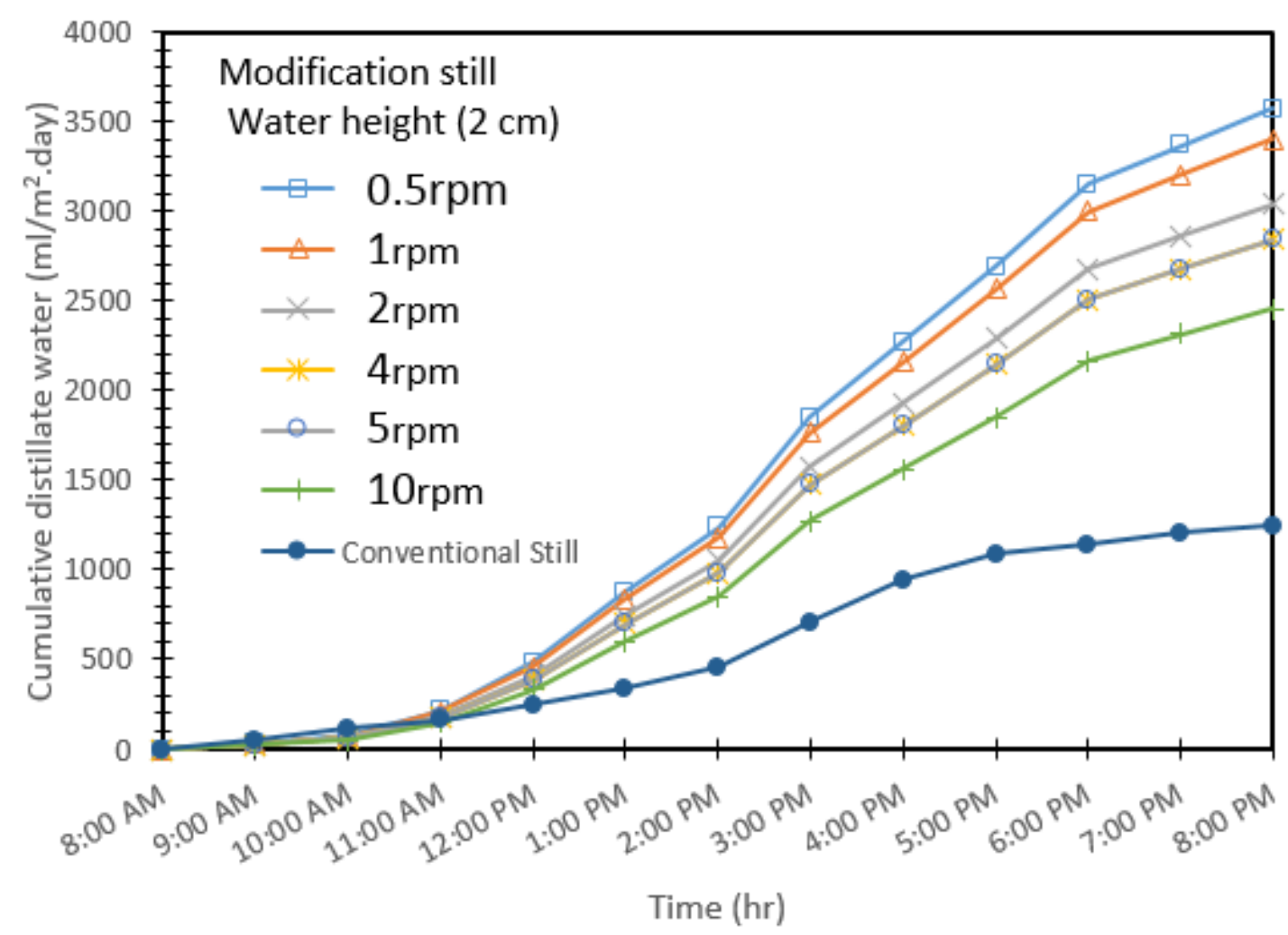

Fig. (8). Effect of a number of revolutions of turning hollow cylinder on the cumulative distillate water output, (Jan. 11-18 2018, Kirkuk, Iraq)

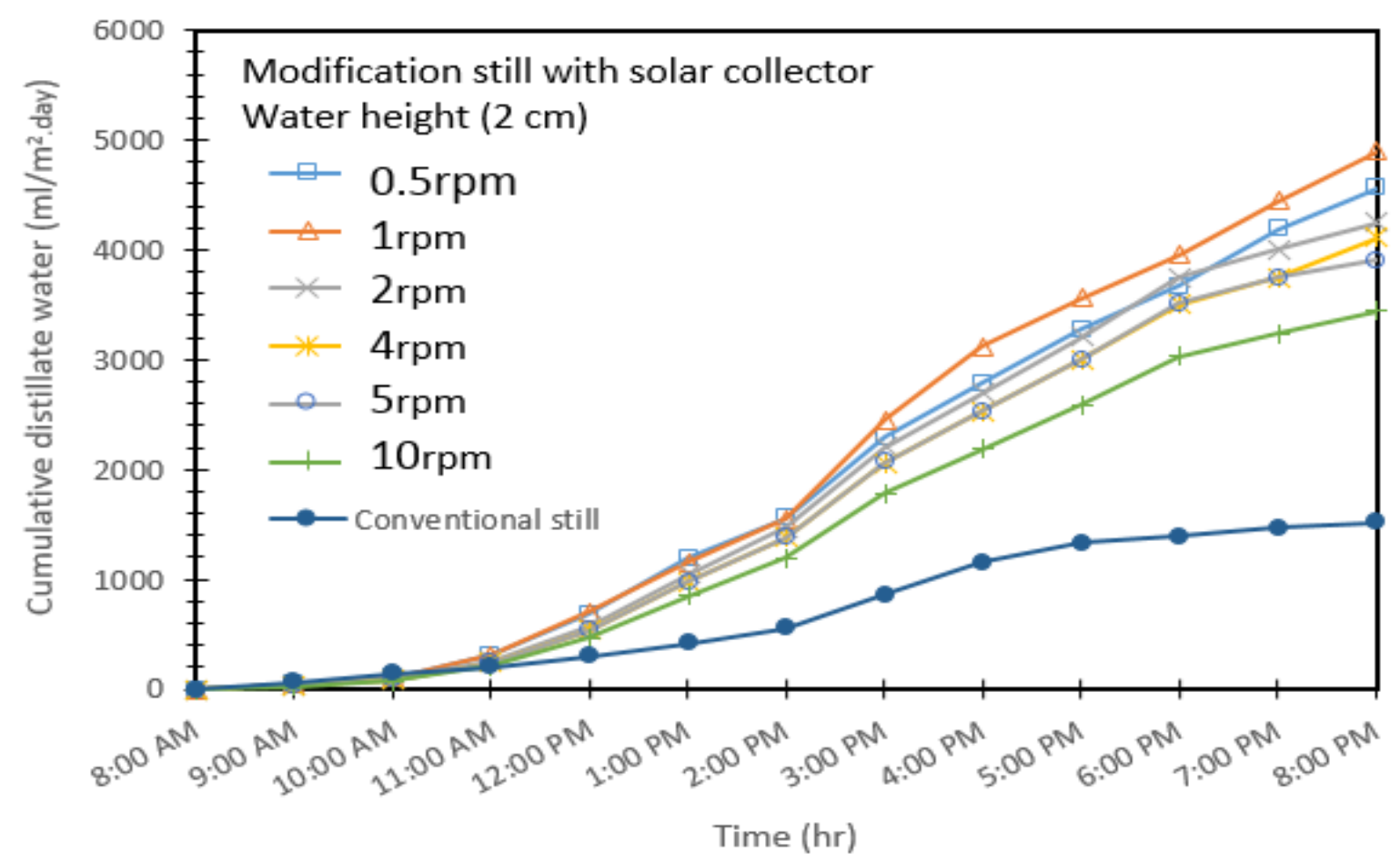

Fig. (9). Effect of a number of revolutions of turning hollow cylinder coupled with the solar collector on the cumulative distillate water output, (Jan. 19-29 2018, Kirkuk, Iraq). 


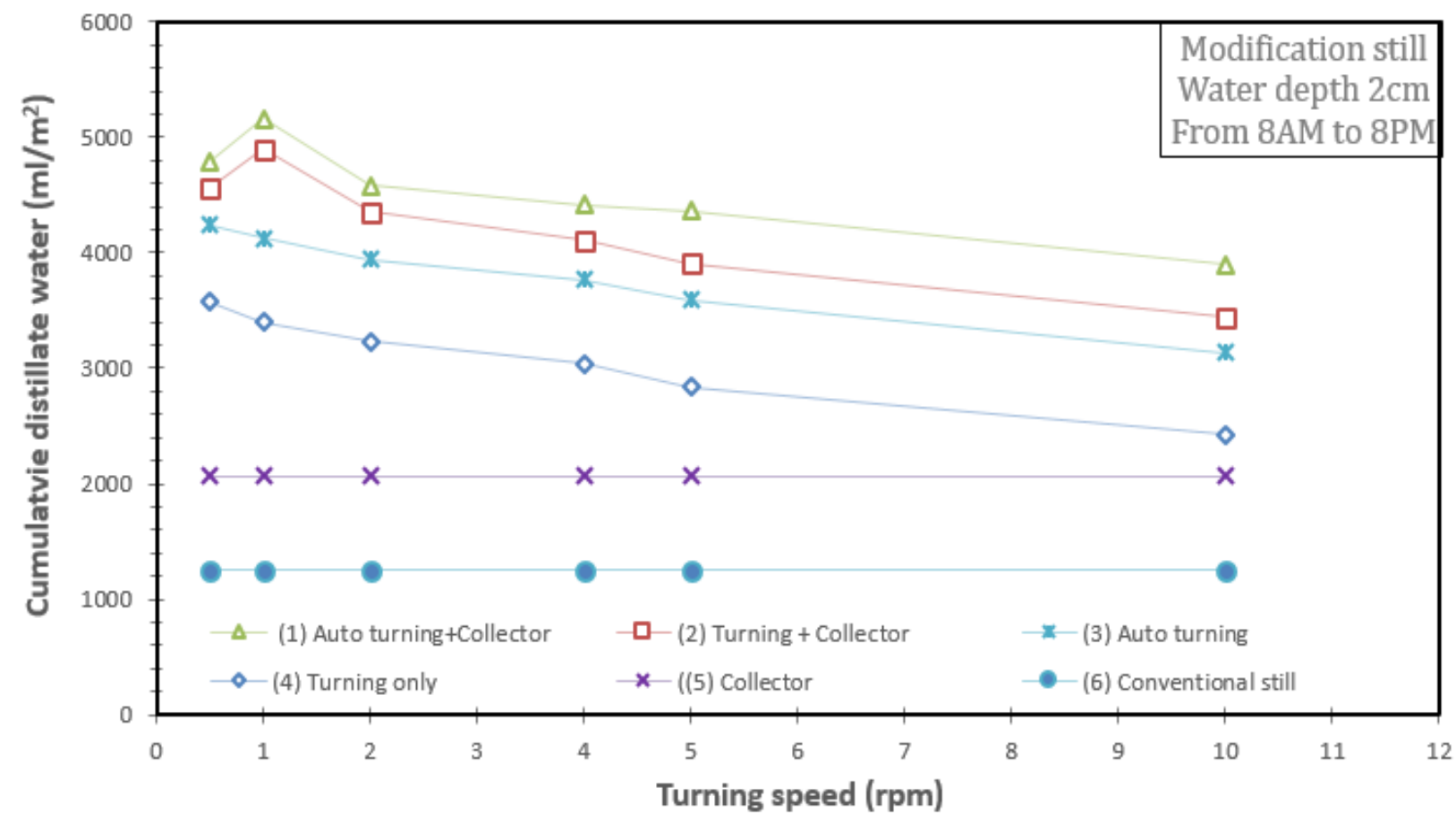

Fig. (10). Variation of productivity with turning speed for different cases of operations (from 27/Jan. to 26/Feb./2018), Kirkuk, Iraq.

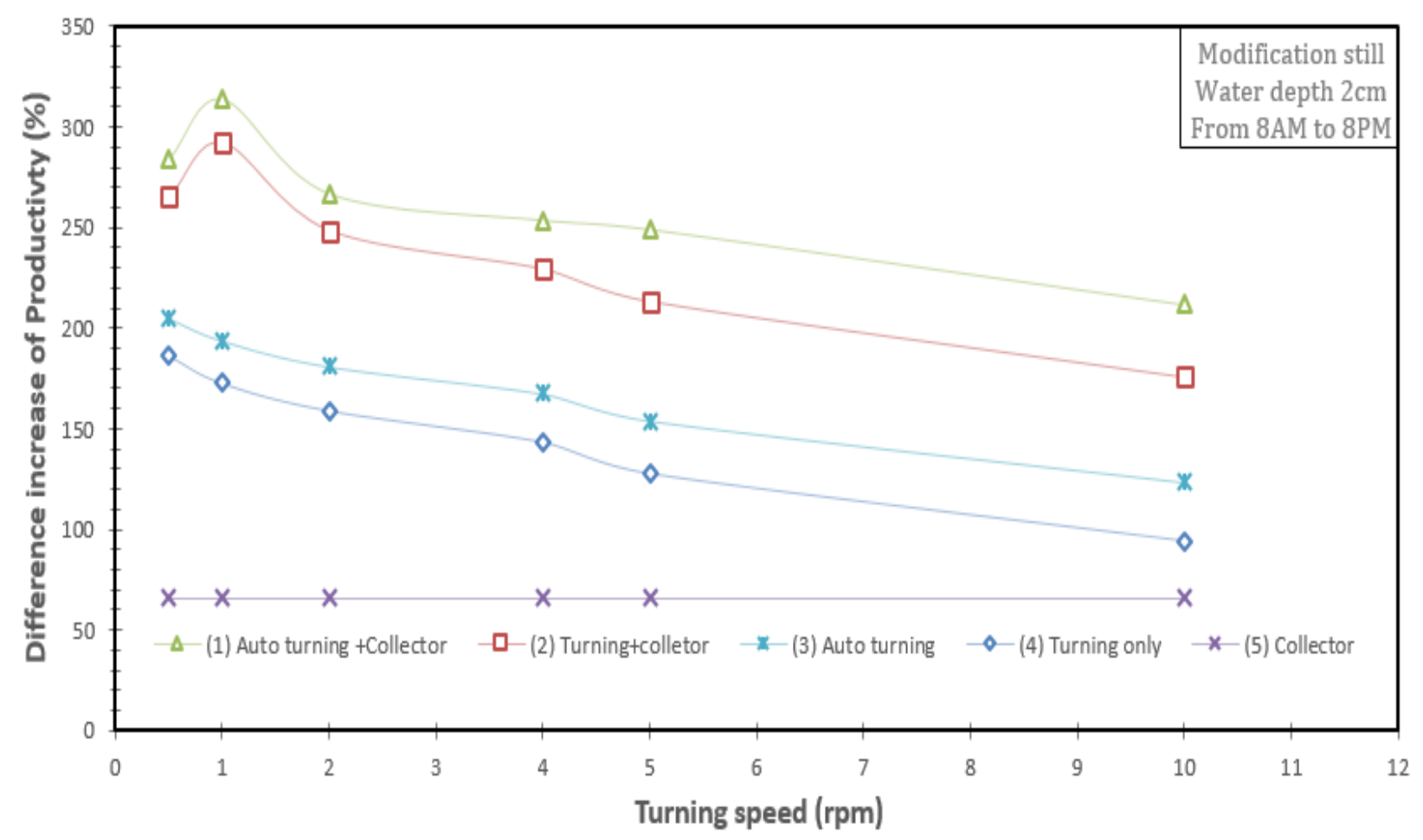

Fig. (11). Variation of the percentage of productivity with turning speed for different cases of operations (from 27/Jan. to 26/Feb./2018), Kirkuk, Iraq. 


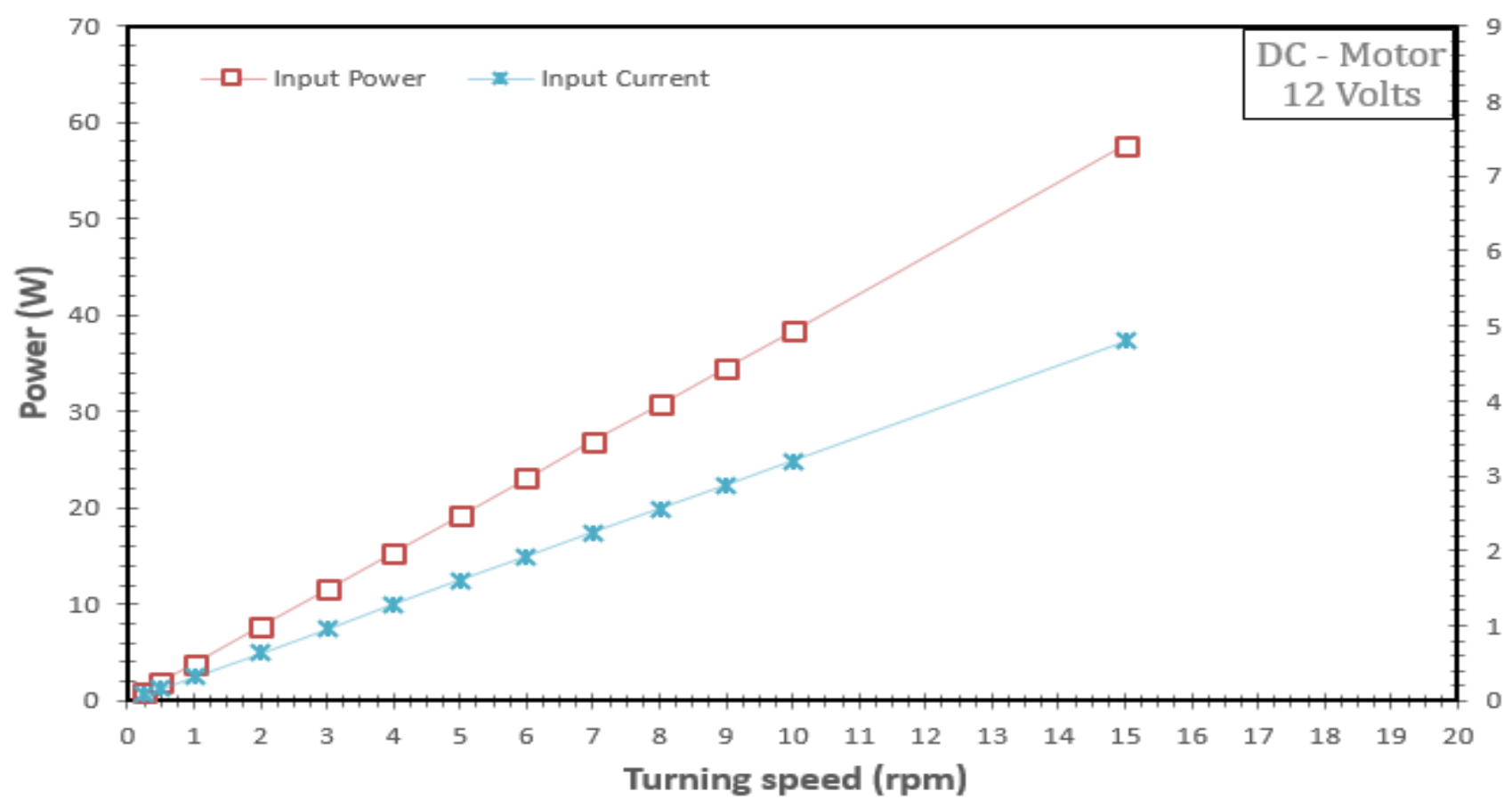

Fig. (12). Variation of power and current for DC-motor on different turning hollow cylinder speed, 2018, Kirkuk, Iraq

Table (1) total fixed cost of modification solar water distillation with photovoltaic panel, battery, flat plate solar water collector and others

\begin{tabular}{|l|l|l|l|}
\hline \multirow{2}{*}{ Seq. } & \multirow{2}{*}{ Materials } & Fixed cost $\left(\mathrm{ID} / \mathrm{m}^{2}\right)$ & \\
\cline { 3 - 4 } & & Conventional & Modification \\
\hline 1 & Galvanized iron sheet & 85,000 & 85,000 \\
\hline 2 & Glass cover and frame & 45,000 & 45,000 \\
\hline 3 & Insulation & 20,000 & 20,000 \\
\hline 4 & Aluminum sheet & ------- & 12,000 \\
\hline 5 & Flat plate solar water collector & ------- & 88,000 \\
\hline 6 & Photovoltaic panel & -------- & 90,000 \\
\hline 7 & DC-motor and pump & ------- & 17,000 \\
\hline 8 & Controller drive DC-motor & ------ & 50,000 \\
\hline 9 & Battery & ------- & 40,000 \\
\hline 10 & Other & 40,000 & 30,000 \\
\hline 11 & Total fixed cost & 190,000 & 477,000 \\
\hline
\end{tabular}




\section{REFERENCES}

Soteris Kalogirou, "Solar energy engineering: processes and systems", First Edition, Elsevier Inc. All rights reserved, (2009).

Abhay Agrawal, R. S. Rana, P.K. Shrivastava and R.P. Singh, "A short review on solar water distillation for getting fresh water in rural area", International journal of current engineering and scientific research, Vol. 3, pp.: 2394-0697, issue-1, (2016).

Himanshu Manchanda and Mahesh Kumar, "A comprehensive decade review and analysis on designs and performance parameters of passive solar still", Manchanda and Kumar Renewables, (2015).

Zeinab S. Abdel-Rehima and Ashraf Lasheenb, "Improving the performance of solar desalination systems", Renewable Energy, pp.: 1955-1971, (2005).

Muafag Suleiman K. Tarawneh, "Effect of water depth on the performance evaluation of solar still", Jordan Journal of Mechanical and Industrial Engineering, Vol. 1, No. 1, pp.: 23 - 29, (2007).

A.Y. Hashim, J. M. Al-Asadi and W.A. Taha, "An attempt to solar still productivity optimization; solar still shape, glass cover inclination and inner surface area of a single basin solar still, optimization, Basrah Journal of Science, Vol. 28, No. 1, pp.: 39-48, (2010).

Hitesh N Panchal and P. K. Shah, "Performance analysis of solar still having different plates", International Journal of Energy Science, Vol. 2, No. 1, PP.: 26-29, (2012).

G.M. Ayoub, M. Al-Hindi and L. Malaeb, "A solar still desalination system with enhanced productivity", Water Desalination and Reuse Research Center, King Abdullah University of Science and Technology, pp.: 1-11, (2014).

John A. Duffie and William A. Beckman, "Solar engineering of thermal processes", Second Edition, (1980).

George M. Ayoub and Lilian Malaeb, "Economic feasibility of a solar still desalination system with enhanced productivity", Desalination 335, pp.: 27-32, (2014).

A. N. Minasian and A. A. AL-Karaghouli, "An improved solar still: The wick-basin type", Energy Convers, Vol. 36, No. 3, pp.: 213-217, (1995). 